\title{
Introducing a teleconferencing network to the most remote region of New Zealand: Or forgiveness is easier to achieve than permission
}

\author{
Jens J. Hansen \\ Westland REAP \\ Community Education Service
}

\begin{abstract}
A few points need to be made about this paper for it is no ordinary paper. Instead it is a script for an audio visual. Thus, it does not read like an academic work. Despite this 'stylistic' aspect of the paper it is none the less a serious attempt to do a number of things. First the backdrop of New Zealand is briefly sketched. Second, some more detailed features of the West Coast are outlined. Thirdly, the paper outlines the political conception, the gestation and finally the delivery of a unique educational package known as the Rural Education Activities Programme (REAP). From this picture a series of educational problems emerge which relate to the West Coast. Probably the most important issue which this paper discusses is the "how to" and "how not to" go about installing a teleconferencing network. And to that extent what emerges is an overall need for educators to adopt a deliberate stance of "political awareness".
\end{abstract}

\section{The Backdrop: New Zealand}

New Zealand - Aotearoa - the land of the long white cloud. Situated on the rim of the Pacific basin, New Zealand is some 1,600 kilometres distant from Australia and a little over 10,000 kilometres from San Francisco, Panama, Tokyo and Singapore. Geographically speaking, this down under country is truly isolated.

In size New Zealand is similar to the British Isles and Japan, but with an overall length of more than 1,600 kilometres New Zealand has a very lengthy coastline in proportion to its area. It is a mountainous country with striking physical characteristics. 
Because New Zealand lies just south of the sub-tropical high pressure belt its climate can be described as temperate. Caught between the hot air masses which drift south west from Australia and the freezing air which occasionally reaches New Zealand from the Antarctic, New Zealand has a sharp climatic contrast between the east and west of the country and the chain of high mountains which extend from the south west to the north west through the length of the country exaggerate this climatic difference.

Overall, New Zealand is lush with flora and rich grasslands. The grasslands, especially the high hills of the country, are incredibly populated by sheep (there are more than 70,000,000 of them) and other livestock such as dairy cows, venison and goats also thrive to give New Zealand a strong agricultural base.

But despite the history of agricultural strength New Zealand is increasingly an urban country. By world standards the population is small - 3.3 million at the end of 1984 and even with a high level of demographic projection, it is not expected that the population will be much more than 3.7 million by the year 2000. The population of New Zealand, like many other parts of the world, can be described as a "multicultural mosaic". The indigenous people of Aotearoa were the Maori - the Vikings of the sunrise. It is thought that Kupe discovered New Zealand about $950 \mathrm{AD}$ and that settlement occurred some 200-300 years later. Subsequently, in 1642, Abel Janszoon Tasman was the first European to sight New Zealand. Following Cook's "rediscovery" colonisation occurred with Maori Culture being largely swamped by the European or Pakeha Society.

Now more than two centuries later there has been a rekindling of interest in Maori Culture so that biculturalism is an aim of the New Zealand education system.

But the ethnic mix of the New Zealand population has many more hues. Approximately 3\% of all New Zealanders are Pacific Islanders. There is a very high rate of migration into New Zealand from Samoa. Nearly half of the Pacific Island population within New Zealand originate from there. And more than a quarter of the Pacific Islanders living in New Zealand originate from the Cook Islands.

The majority of these people are centred on Auckland - New Zealand's largest city. It is a characteristic of New Zealand that few Pacific Islanders and Maoris live in the South Island. And even fewer live within the most isolated province of New Zealand - the West Coast. 


\section{The West Coast: A Profile}

The West Coast of New Zealand is a long thin province situated within the South Island.

The West Coast as a region lies between the Tasman Sea and the Southern Alps. The Coast is characterised by narrowness (it is only $40-100$ kilometres from west to east) and it is also characterised by great length (560 kilometres from north to south).

The West Coast is characterised by a very small proportion of arable land; in fact less than $5 \%$ of the total land area is in grass or crops as compared to $50 \%$ for New Zealand as a whole. Indigenous forests and mountains account for $61.4 \%$ of the land and only $0.2 \%$ of the land consists of residential builtup areas compared to $2 \%$ of land usage for residential purposes throughout the rest of New Zealand. So what we have is a long thin territory with $88.4 \%$ under Government control and a small, widely spread population. This compares to a national figure of $33.9 \%$ state control.

The Coast is rich in history, and scenically very beautiful. It also has a history of exploitation based on the extractive industries of timber, coal and gold. In the early days boom gold towns mushroomed almost overnight as men, exhausted by the sheer act of getting to the West Coast proceeded to rape the land in pursuit of that precious metal - "gold". At the peak of the gold boom in the 1860's, the population on the West Coast reached 25,000 with the majority being clustered near or in the main towns of the West Coast.

After the gold boom had yielded its golden ore, coal mining and timber production became the main thrust of exploitation but for a brief period during the depression of the 1930's gold seekers on the West Coast again swelled in numbers to lift the population to an all time high of 40,000 people. Now the population is in the vicinity of 36,000 people and the present population of the West Coast has a series of demographic features.

There is an over representation of males in all age groups. The population also has a high rate of fluctuation which is consistent with the "boom and bust" nature of the extractive type of economy found on the Coast. As well there is a high rate of geographical mobility with many Coasters (especially the younger age group) leaving the area for a greater choice of job opportunities. They also leave the Coast to attain advanced training or tertiary education. 
But just as there are those who leave, so there are those who deliberately come into the Coast. The sheer scenic beauty of the West Coast, its relative isolation from the rest of New Zealand and its sparseness of population has made it an "out of the way mecca" not only for tourists but also for those who might be referred to as "alternative lifestylers". Many of these relative newcomers to the West Coast have been at the vanguard of precipitating recent development in aesthetic areas such as pottery, painting, jade, and craft cooperatives.

And of course there are those who seek to catch "whitebait" - a small 45 $\mathrm{mm}$ fish, which, while not exclusive to the West Coast is none the less much more sort after in Coastal rivers than anywhere else in New Zealand. But there is also a cluster of immigrants $\mathrm{w}$ ho have moved into the Coast who are relatively unskilled and who have been attracted to the West Coast because of cheap housing. Many of these people are state beneficiaries who from time to time are able to secure part time employment in a range of occupations.

Another demographic feature of the West Coast population is that there is a high proportion of retired people and beneficiaries. In fact there are proportionately more of these two groups living on the West Coast than in the rest of New Zealand.

All of these demographic features and the unique geography of the West Coast have special implications for those involved in the business of providing "learning activities".

Anyone working in the adult learning business on the West Coast must consider the employment and unemployment profile of the Coast population and a number of features stand out. First, there is a higher than usual level of Government involvement in employment with $32 \%$ of the work force being State servants (the national proportion is 20\%). Second, the very high proportion of state owned land and the region's extreme isolation and long thin terrain means that extra services in health and transport are needed.

Most Government servants live in Greymouth and to a lesser extent Hokitika, but concentrations are also to be found in the more remote areas such as Whataroa, Hari Hari and Haast where highway construction workers are clustered. Their role in keeping transport routes functional is very important - especially as with a very high rainfall, floods and slips can close the single main highway which stretches from one end of the Coast to the other. 
Unemployment on the West Coast is currently running at $9 \%$, and has struck almost exclusively at the young - those under 25 years of age. Government instituted short term employment projects have recently been phased out in favour of Training Assistance Programmes but these are controlled by a Non Educational Department - the Department of Labour. There is widespread dissatisfaction amongst many community agencies with respect to the whole area of unemployment, and erosion of self worth is experienced by far too many young people. This stressful situation is currently being compounded by a massive state reorganisation of Government Departments such as Forestry, Lands and Survey and the Post Office. They are being formed into Corporations and the staffing reorganisation will directly effect approximately $13 \%$ of the total labour force of the West Coast and of course, the down stream impact will affect even more people.

So all in all there is on the West Coast a great deal of sensitivity and cynicism about Government involvements and Government policy. People on the West Coast argue fiercely that bureaucrats and central Government have little or no understanding of what the real issues are within this isolated region. After all they - the bureaucrats and politicians - don't live there. Certainly the current reorganisation of Government services by the present Labour Government are expected to have considerable flow on effects within the West Coast and perhaps these will be more significant on the Coast than in any other region within the country.

In a region as isolated as the West Coast, transport and communication links are important. The West Coast has a good quality roading system which stretches the length of the region but roading costs are the fourth highest in the country and on a per capita basis the costs are double the next level of expenditure. There are only four routes into the West Coast two entries in the north - one entry somewhere about the middle at Arthurs Pass and one in the south at Haast. During winter these gateways into the district are occasionally blocked by snow. For this reason the daily air commuter service to and from the West Coast is an important link in and out of the region.

But other communication links are very poor. Much of the West Coast cannot receive radio reception - principally because the Broadcasting Corporation has not yet been able to afford to provide FM transmission to this rugged and difficult terrain. Also, in many areas, it is only possible to receive one Television Channel and so isolation becomes even more pronounced. 
The isolation is rather exaggerated by the parochialism which is frequently encountered on the Coast. West Coast parochialism is not only based on districts - and each district has its own unique history and each district also differs greatly in terms of its economic sources - but also, suspicions and rivalries exist between the traditional West Coaster and "newcomers". "Newcomers" are folk who have moved into the area either because of marriage or through occupational promotion. And there is an even greater suspicion of "transients" who can be described as those who have moved into the West Coast for a short period of time on promotion and then almost as quickly move out of the West Coast - again on their way up the promotional ladder. Most of these "transient" people are civil servants. Most live in Greymouth and Hokitika.

Given this thumb nail sketch of the West Coast it is hardly a surprising observation to note that delivering any form of adult education service is very difficult. The region is extensive with a small population base which is far-flung and has large extremely isolated pockets. There is a marked level of state control and a high proportion of State servants who are suspiciously regarded by a strongly conservative element of indigenous "locals". So introducing educational change is very difficult. It's not surprising that the Coast, with its long history of exploitation by "outsiders", has caused the "locals" to feel quite ambivalent about the future of the West Coast and to feel quite suspicious about the place of "newfangled education programs" - especially if such programs were imposed on them by Central Government as an apparent political ploy.

\section{The Rural Education Activities Program}

REAP, or to give it its full title - the Rural Education Activities Programme appears to have been just such a politically determined educational strategy. REAP was conceived in 1978 by the National Government of the day when they determined, just prior to the forthcoming elections of the time, that additional educational resources should be put into some rural areas in order to try to meet the needs of those areas across a broad educational spectrum.

It has been claimed that REAPs were put in place to compensate for an apparent decline in rural education and they were also introduced because it was assumed that education within a rural area was in some way "deficient" when compared to the advances which were taking place in metropolitan centres and larger provincial areas.

And so, thirteen REAPs were scheduled to be put in place throughout New Zealand over a four year period. Interestingly, with the exception of the West Coast, each of the REAPs was situated in a highly marginal 
electorate. Interestingly also, the number of staff originally allocated to the Westland REAP (4.5 staff) was the second smallest parcel in the country. The rule of thumb appears to have been that the more marginal the seat, the greater the size of the staffing package. But because no minutes were kept of the original meeting which was held between the Minister of Education and his Departmental officials, no one really knows precisely why some REAPs were given larger amounts of staffing than others.

What happened was basically very simple. Each of the designated areas was invited to establish a Management Advisory Committee which, in theory at least, was to draw its representation from a wide range of groups who were interested in education. It was then to be the role of this Management Advisory Committee to develop a more coordinated and more flexible education service within its district - an education service which would address learning needs from early childhood through to post-secondary school education. If you like - a total "life long learning" package was being mooted.

So even though Management Advisory Committees frequently were loaded with teachers and not the community, they were able to appoint staff and there are 92 REAP teacher equivalents in all. Throughout New Zealand there are Community Pre-School Workers whose job it is to facilitate the provision of early childhood education. Community PreSchool Workers are also expected to heighten community awareness of the benefits of pre-school education.

Management Advisory Committees in some instances were also able to appoint a Visiting Teacher. A Visiting Teacher serves as a go between from the home and the school for those children who are having difficulties either at home, or at school, or in both settings. In effect a Visiting Teacher is an "advocate" for children and under normal circumstances would not be found in a rural situation except for the extraordinary provision of this compensatory package.

Another component allowed three of the thirteen REAPs to appoint an Outdoor Education Coordinator who works either on a full or a part time basis. They were appointed so that outdoor learning could be promoted both within formal school institutions and throughout the non formal learning community.

All of the thirteen REAP packages have a Community Education Organiser. The role of the Community Education Organiser is, broadly speaking, to promote, to facilitate and to co ordinate all life long learning activities within their region. The Community Education Organiser in each 
of the REAPs is the only permanent position to be established. All of the other positions are short term contracts and may involve part time employment.

There are some additional components too. Many of these are traditionally tied into formal education institutions such as elementary and post elementary schools which in New Zealand are referred to as Primary and Secondary Schools. Some REAP areas have been afforded the luxury of being able to appoint Advisers to Schools or additional teaching staff to work in special needs areas within secondary education. Yet other REAPs have additional and special staffing allocated to them because of their "rural" nature. Altogether eighteen such staff have been allocated throughout ten of the thirteen REAPs. The Westland province of the West Coast, despite being the most rural region in New Zealand has not been granted any staffing from that category.

Finally, there is a component which is common to all of the REAPs and which is called "Liaison". In theory, liaison allows for innovative educational development and allows for the employment of temporary staff on a half or one day, or a one week, or even a several week basis so that innovation and linkages between the various sectors of education can occur. In practice, the size of the liaison component is allocated as a hill time teacher equivalent. This means that three of the thirteen REAPs have the equivalent time allotment of three fulltime teachers each, or a total time allotment of 600 teaching days each. These 600 days are able to be used for the hiring of staff.

It is a curious phenomenon that the Coast has very little of this "liaison" componentry and therefore "liaison" is almost exclusively used by primary and secondary schools. Any attempts by pre and post school education to gain the use of this flexible component have been vigorously resisted by the formal institutionalised learning sectors.

In the case of the West Coast there are in fact two REAPs. Because of the sheer size of the region there is a REAP which covers the northern sector of the West Coast. This is known as Buller REAP. It has a staffing package of 6.7 teacher equivalents. It has a population within its catchment area of around 12,000 people and when the scheme was first mooted the Buller area included a part of the electorate of the then leader of the Opposition Party. That northern seat was considered to be marginal. It is still considered to be marginal.

The balance of the West Coast is the domain of Westland REAP. The Westland REAP staffing package originally comprised 4.5 teacher equivalents but later a 0.5 allocation was added so that a half time 
Outdoor Education Coordinator now works within the region. Westland has the distinction of being in the only safe Labour held electorate which w-as allocated a REAP.

So REAPs were put in place in order to compensate for supposed educational deficiencies within rural sectors and by placing REAPs strategically, political advantage appeared to be gained by the Government of the day. As demonstrated, the size of the staffing package varied from region to region with the only "safe" Labour seat being accorded the second smallest of all of the packages. Also that staffing package services by far the most remote and the largest region within New Zealand. So it is not surprising to find that there are a number of educational concerns which pre-occupy REAP educators on the West Coast and perhaps it's not altogether surprising to discover that educational technology may have a very important role to play in addressing some of these concerns.

The first and most paramount of these educational concerns is the issue of distance and this problem has already been more than adequately demonstrated.

The second West Coast educational concern is that of costs. Paying for a tutor to travel to a class in a remote village is a very costly exercise but equally, it is an extremely expensive exercise to expect students to travel to a centralised township in order to participate.

At current 1986 New Zealand Government travel rates, the cost of sending a tutor on a journey involving some 400 kilometres of travel in a $2000 \mathrm{cc}$ car is $\$ 256$. It's not difficult to work out that the costs incurred by a class of 8 - 10 potential consumers - each having to travel a similar distance from a series of localities - is also very expensive. In fact, it's not surprising that the arithmetic shows why more often than not, the high costs of travel prohibit educational delivery to isolated areas - especially when travel is a "user pays" levy. So cost, (especially travel cost) is the second West Coast educational concern.

A third education problem is the scarce availability of "people resources". Within a rural area people resources are more geographically dispersed than within an urban setting. So it's important that ways be found of "freeing up" the expertise of, for instance, the computer programming expert who lives in town number one. By "freeing" that expert, town numbers two, three and four can also get some "bites" of that form of expertise. But by the same token, it is just as important that town number one should be able to tap the skills of other resource people who live in each of the other towns. 
Then of course, there is as a fourth issue; the need for coordination and planning. Today, education resources are becoming scarce, but educational needs appear to be expanding. There is an "effectiveness and efficiency" cult which appears to be thriving. So obviously in this tight economic climate, good planning is an arch enemy of waste. In fact it could be claimed that the very best planning of all becomes facilitated primarily when a multi-disciplinary approach is adopted.

For this reason it becomes important that key personnel within the various Departments of Government communicate with each other so that each Department has some idea about the concerns, issues, and even aspirations of other Departments. In fact, a necessary pre- condition for effective and co-operative planning is the process of deliberately sharing information. This is especially important in education where there is a responsibility for developing relevant, client centred learning menus. And when the learning menu is client prescribed and owned, it can become a powerful aid to regional and community development.

So on the West Coast there are at least four relevant issues which education ought to be addressing. As you have already discovered overcoming distance and isolation is the most pressing of these issues. But there is also the ever common concern about finance and there are the intertwined themes of unlocking scarce and distantly distributed "people resources" as well as making it possible to access skills right throughout a region. Finally there is the matter of coordinated planning.

But the question of how to both discover and implement good strategies for addressing all of these concerns is not necessarily a vexed one. The common thread for each of the concerns is a need for "good communication".

Now it transpired that the Westland REAP Community Education Organiser learnt that in New Zealand, innovations in developing teleconferencing were being pioneered by the University of Otago Extensions Department. So here was a possibility to be explored.

As it happens the Westland REAP Community Education Organiser observes three basic Community Development procedures. He has an open door policy and tries never to say no to any request. He deliberately tries to increase a consumers options - even if the consumer elects not to pursue them - and he operates on the belief that forgiveness is easier to achieve than permission. In other words - if it seems justifiable - do it and worry later on about the bureaucracy giving the go ahead. 
And so with these rules of thumb firmly entrenched the Community Education Organiser decided that the best thing to do with respect to finding out about teleconferencing was to actually visit the University. By experiencing the technology and by visiting the experts it should be possible to learn about how to establish a teleconferencing network. The fact was that the Community Education Organiser felt that this system might be able to go some way towards improving communications within the Coast. Improving communications would of course also address the four principal REAP Community Education concerns of the West Coast. And better still, a West Coast network would become even more relevant when a planned 26 terminal teleconference network eventually became established, and linked all of the main urban centres in New Zealand.

In fact the advantages of developing a West Coast teleconferencing network appeared quite numerous. Access barriers to information would largely be removed for even the most isolated parts of an isolated region. High savings in travel costs would be realised and yet more frequent dialogue with a network of contacts would be maintained. Resource people would be able to spread their talents and skills and the planning and holding of meetings between areas and organisations would become logistically easier and cheaper. But how to persuade the politicians and various Departments of these self-evident advantages? That was the question!

And this is what happened. First of all the University of Otago was asked whether or not their brand of audio teleconferencing hardware was available for purchase. Obviously, if the Unitel system was only available on a lease basis then it did not follow that the West Coast would necessarily be allowed by them to lease their resource.

In the event the University of Otago agreed to make their Unitel hardware available for purchase by the West Coast. The price per unit was in the vicinity of $\$ 1,300$ New Zealand. Each unit included a 4 wire Unitel audioteleconferencing control box; 4 push to talk teleconferencing microphones; extension couplings, and an extension speaker. A slide system could also be operated from any teleconferencing point. The advantage of the University of Otago teleconferencing system was that a very high level of audio quality had been achieved.

Obstacle number two was to find the money to pay for the hardware. Three units at approximately $\$ 1,300$ each may not appear to be very much to a large organisation such as a University or a Technical Institute. But for a tiny organisation such as Westland REAP(and remember that the Community Education component is only $20 \%$ of the entire Westland 
REAP package) to find that amount of money for anything is not easy especially in a climate where cash resources are shrinking and there is a total annual Community Education Budget of less than $\$ 20,000$. The problem was further complicated because the intention of establishing a teleconferencing network necessarily meant linking Westport with Greymouth and Hokitika as a minimal first step. And of course Westport being in the Buller, does not fall within the territorial boundaries and jurisdiction of Westland REAP. So here was another snag.

The snag was overcome by approaching an organisation which was common to both the Buller and to Westland - in this case the West Coast United Council. The United Council is tantamount to a Regional Planning Authority and has oversight of regional planning, regional development, and civil defence. The Council itself is made up of representatives from each territorial local authority in the region.

The West Coast United Council had in 1978 been given a one off Central Government Grant of $\$ 13,000$ for developing community education throughout the Coast. The money technically did not belong to the United Council but they were the designated custodial statutory body. A Regional Committee had been put in place to oversee the dispersal of this funding but that Committee had dropped out of existence through inactivity. It had not met for some eighteen months and it had certainly not considered what to do with the residual funding after an expensive survey had been carried out. A South Island University College had researched the continuing education needs of a very small sample of people in Westport, Greymouth and Hokitika at the request of the Committee.

In effect there was some $\$ 6,000$ left in the care of a sleeping organisation which conceivably could be resurrected. Thus, the West Coast United Council Community Education Advisory Committee was reconvened. The term Community was subsequently dropped so that the Advisory Committee became an Education Advisory Committee with a much broader brief than community education.

The Community Education Organiser of Westland REAP became the prime resurrector, Convenor and Chairperson of that Advisory Committee and the West Coast United Council gave backing to the re-formed Committee to complete a task which had been proposed and then neglected by the original Committee: namely, to investigate alternative methods of educational delivery.

In other words here, at once, was a regional organisation which could take up the ownership of the idea of a teleconferencing network and they could fund any subsequent developments. The net result was that in February 
1984 the West Coast took the significant step of not only inviting itself into the proposed national teleconferencing network but also, it took a major step towards developing its own independent system.

It did this by arranging a demonstration of the teleconferencing technology in Greymouth and not only was the University of Otago and its seven local constituent teleconferencing outposts hooked up but so too was the New Zealand Parliament. In addition, the entire West Coast United Council participated in the demonstration together with Hospital Board members, Federated Farmers representatives, industrial and union leaders, representatives from teacher organisations, and also there were people from most of the Government Departments which operate on the West Coast. Both the then Minister of Science and Technology and the Postmaster General of the day took part in the teleconference as did the local Member of Parliament and the Chairman of the New Zealand Futures Trust - Professor James Duncan.

All together more than 90 people were able to share the same experience from eight vastly spaced geographical points.

The upshot of the demonstration was that the West Coast United Council not only endorsed the role of the special Education Advisory Committee but also, they endorsed an input of finance for the purchase of teleconferencing hardware.

And so a permanent internal West Coast network of 9 teleconferencing terminals became proposed with the first 3 terminals now having been put in place. These Phase A terminals are situated in Westport, Greymouth and Hokitika but the United Council Education Advisory Committee plans to have two other phases of installation. Phase B would see the installation of teleconferencing in Karamea, Reefton and Hari Hari and Phase $\mathrm{C}$ would see terminals put in place in Haast, Fox Glacier and Otira. When all 3 Phases have been installed, all Coast people should be no more than an hour from a terminal.

But, as we shall see, the implementation of this scheme has not been straight forward.

\section{Implementation Problems}

The years 1984 and 1985 then, were significant because agreement had been reached with the University of Otago so that their technology was made available for the first time to an independent network; and funding had been found for initial hardware purchase. But there remained two 
other problems. The first was to find funding for the operating costs of teleconferencing, and also there was the second problem of persuading a conservative public that here was an additional option for communications.

With regard to the first of these problems - operating expenses - an important input was won in 1985 from the Department of Education. They gave a one-off grant of $\$ 8,000$ so that a majority of the running costs for the first year of operation could be met. The idea was to have a permanently leased or dedicated toll line operating between Westport, Greymouth and Hokitika and the Education Department's funding was seen as a guarantee against loss for the first year. Subsequently, it was hoped that the system would become mainly self supportive and minimally dependent upon direct Government infusion of money.

But as the old saying goes "the best laid plans of mice and men gang oft astray". The West Coast United Council Education Advisory Committee had early recognised that a unified approach from all quarters of the West Coast region was essential if the network was to succeed. In fact, just as it was recognised that it was important for geographical sectors within the West Coast to co operate; so it was also recognised that Government Departments who stood to gain by the use of this new communications infrastructure should ideally collaborate. They should do this especially with respect to forward planning and policy development. It was argued that communications planning had to occur if only to avoid the duplication of networks and systems. The process was likened to ensuring that two trains are not sent each day when one will do.

So even though this new technology was available to educators within the West Coast and could immediately increase their teaching options, the challenge for the community as a whole centred - in the view of the West Coast United Council Education Advisory Committee - on achieving the most efficient and socially desirable method of implementing communications for the total community. And in that regard the Advisory Committee believes that the education sector is but a part of the total community.

What happened next was that a single teleconferencing terminal was installed in Greymouth. This was located in one of the oldest buildings in the town. The building was being slowly transformed from a disused hostel into a struggling community and cultural activities centre. From that centre linkups occurred with the University of Otago for a number of teleconferencing courses. These included some Post Graduate Medical 
seminars, and some Agricultural Development work. The University of Otago thus provided tuition to West Coast students who learnt together with students from a whole set of other interconnected townships spread throughout the lower South Island of New Zealand.

At that time - within the West Coast - other things were afoot. Westland REAP had been granted new premises by the Department of Education but there was a period of around 9 months before staff were able to occupy the new buildings. The previous leased office had become very cramped and it was felt that it would be uneconomical to temporarily install teleconferencing. So it was decided to wait until the shift into the new premises took place.

At the same time, Buller REAP was exploring the possibility of gaining new premises. In the case of Buller, buildings and administration were governed by a different Regional Office to that of Westland and the Buller building proposal took considerably longer to gain approval than it had with Westland. In fact the Buller REAP building will not be officially opened until February 1987 which is some 16 months later than the opening date of the new Westland REAP centre.

For this reason, there has been a substantial time lag in putting into place the proposed West Coast "inter-institutional" teleconferencing network. For a while Greymouth and Hokitika were connected and a temporary terminal was also installed at the Buller High School in Westport. Hindsight has shown that this move was quite unsatisfactory because not only was the Westport connection unusable during school hours, but also it was a long way removed from the community of potential users within Westport. Also, the actual cost of a leased line to Westport was the most expensive link to hire.

And so, after a prolonged period of waiting for the Department of Education to finalise building arrangements for Buller REAP - and for Buller people to link into the system - it was decided to pull the plugs on all three terminals: to temporarily relinquish the lease of the dedicated toll lines. And that is where the matter currently lies.

But in connecting the terminals on a temporary basis some valuable lessons were learnt. Firstly we have learnt that it is essential that a total network be ready to put into place before any attempt is to be made to market this kind of educational commodity for community consumption. After all, without the factor catered for what is there to market? 
We've also learnt that if the total network is not ready to be put into place then maximum value for taxpayers money will not be gained. The reasoning behind this observation goes like this. When a customer leases a dedicated toll line, they lease the right to use that line as much, or as little, as they wish to on a 24 hour a day basis. So if the toll line is not used at all it still has to be paid for. It therefore becomes an expensive commodity and an unwise use of taxpayers money. On the other hand if the line is used for 24 hours a day - it is obviously good value for money.

It must be said that in the case of Westport, for three months there was literally no use of the teleconferencing facility at all. The Westport "temporary" connection was therefore, an expensive experimental failure. However in the case of Greymouth and Hokitika there was daily and extensive use of the teleconferencing facility and we learnt a lot.

We learnt that teleconferencing has a major use in the co-ordination of activities. Through teleconferencing immediate communication between learning centres became possible. For this reason it became possible to coordinate the use of visiting tutors, to standardise course fees and activity charges for events being repeated throughout the region and perhaps most importantly, professional isolation was not only overcome, but professional enrichment between rural educators began to develop.

The whole exercise however posed a chicken and egg quandary. Without all three terminals being actively used and totally available, it was not possible to achieve the total co-ordination which we quickly recognised to be possible. Instead, parochialism and inter-regional differences were heightened rather than submerged. And also we found ourselves rather clumsily trying to persuade potential user groups like Law Societies, Nursing educators, Teacher groups, Unions, Voluntary Welfare agencies, Banks and Mercantile groups that here was a "not yet totally connected" facility which they should use. We were trying to operate on the assumption that "when the product is finished and connected it will be all right. Just take our word for it". So without any doubt, the most important thing that we have learnt is that if you wish to persuade others to use educational technology then you must do so on the basis of having everything totally in place. In other words - don't have any missing pieces or makeshift linkages.

We also learnt that as a teaching vehicle, teleconferencing was a useful tool - especially if other more traditional techniques such as group discussions were dovetailed into a session - so that the learning event was not exclusively teleconferencing. 
And we found that children's interest could just as easily be sustained as that of adults where the teacher was vibrant. We proved this when we used New Zealand's foremost astronomer to run a series of seminars on Halley's Comet with children and adults alike.

Finally we discovered that when a network is left permanently on - there needs to be a kind of "paging" call sound for each terminal so that people at a teleconferencing station actually know that someone wants to talk to them. If you like - there is a need for technocrats to invent a teleconferencing telephone ring.

What we had set out to achieve was the large scale use of our teleconference facility because it could serve as a "distance cruncher"; could improve inter-institutional communications and it could broaden access to educational menus for consumers.

In noting this, we wanted the operating costs to be paid for on a user-pays basis - but we also wanted to rewrite the old Chinese proverb of "many hands make light work" into "many fingers on 'push to talk buttons' make for light individual payments". We also hoped to partially meet operating costs by making the facility available to business firms, because the Unitel teleconferencing network, as a four wire system, allows for adventurous configuration. In other words, computer terminals can be run off a 4 wire system and what we would like to see is an after hours sub-leasing of the dedicated network by commercial agencies. This would be a practical application of the planning principle identified earlier - namely that two train lines should not be built when only one is required.

But what we encountered was a form of "educational myopia".

In fact, the most important task which distance educators and educational technologists should talk about right now must be the achievement of a paradigm shift of opinion so that "educational myopia" is replaced by "educational farsightedness".

James Lange at a Conference on satellite communication for Australian Tertiary Education referred, in May of 1984, to "educational myopia" with respect to technology, broadcasting and administration. Lange argued that progress can only occur when short sightedness has been overcome. Let's extend his argument and claim that education will only be able to stand equally with other community interests in laying claim to a slice of the growing communications infrastructure when it has learnt to become 
farsighted! Let's also advance the argument that educational progress will only begin to keep pace with the real world when a farsighted stance is purposefully sought after.

In so far as the West Coast experience is concerned there is little doubt that educational myopia is present. Teachers' organisations found it difficult to think in terms of teaching unseen pupils; some committees preferred to maintain traditional face to face dialogues and too bad about the travel... and distance education institutions in the main talked about gimmickry which would not be able to replace the traditional mail-outs of student learning sets. But despite these doubting stances there are also some hopeful signs that farsightedness is beginning to emerge in some quarters.

\section{Future Prospects}

In 1985 the Inaugural Conference of the Distance Education Association of New Zealand was held in Hokitika on the West Coast. This Conference was especially significant because it meant that the traditional correspondence teaching institutions had been moved to discuss distance education in a rural setting rather than expecting rural students to visit them within the sanctuary of their own powerful institutions. And importantly these institutions were told by their consumer public that institutional myopia is not acceptable.

Also in 1985 the Minister of Education, the Honourable Russell Marshall set in train a survey into the provision of continuing education and an assessment of continuing education needs for the West Coast. The findings of this survey were released by the Minister in May of 1986. What was released was a proposal to establish a New Zealand pilot - a West Coast Regional Learning Service or a distributed West Coast Community College without walls.

A principal recommendation which emerged in the Report to the Minister of Education was that the proposed Service should "make use of the existing teleconferencing facility already installed in three locations, extend the network, and widen the range of equipment to include computer modems, information data bases and possibly facsimile document reproduction". One might even suggest that "videodiscs" should be added to that fine array of high tech equipment.

Not surprisingly the key proponents of the teleconferencing network submitted a supportive response to the Minister on this matter. They not only endorsed the proposal but also went so far as to claim that "here is 
presented a unique opportunity to not only develop a world first 'educational structure' which caters for all ages and stages of learning, but also, in this instance, communications become axiomatic in determining the success of whether or not this whole event will work. Research shows that nowhere else in the world would there be a system which would cater for pre-school education right through to formal and non formal continuing and community education whilst harnessing new age technology".

So there is perhaps some farsightedness in the offering. And while new age technology is without doubt an important ingredient with respect to the development of a West Coast Regional Learning Service it must also be said that the process which is brought to bear in developing this service will be equally important. If the learning service is implemented from the top downwards - then it will in all likelihood fail to reflect the needs of the community and will perpetuate educational myopia. But if a grassroots upwards approach is used then not only will the integrity of the West Coast's 39 small community villages be preserved, but also the people as members of the region will have owned the process from the beginning and will have facilitated educational farsightedness.

We - those of us who work in education and who are by virtue of our specialised knowledge on the subject of learning are seen to be "authoritative" and are therefore put "in authority" - are usually aware of the numerous possible technical configurations which can enhance learning. We know for instance that a 4 wire system can link high quality audio communications with videotex, computers, electronic blackboards, videodiscs and so on and we also know that as costs diminish, availability to the learning community ought to increase - and we know that literally the sky is the limit. But do we have the policies that will enable this - do we have permission to proceed?

PEACESAT the University of Hawaii's communication satellite has now outlived its usable life. Now, AUSSAT beckons and in the foreseeable future we must surely address the possibility of linking a developing New Zealand teleconferencing network with the already extensive Australian network. But are we prepared for this?

Are we, the so called experts or authorities, constrained by tradition, inflexibility, a lack of co-ordination and educational myopia? 
Perhaps this editorial by Dave Meacham, the Editor of the Australian and South Pacific External Studies Association Journal, says it all. The editorial is headed: KEEP YOUR DISTANCE, and it is subheaded Educational Technology: bandwagon or hearse; telematics or masturbatics!

The editorial reads like this:

At a recent Conference on distance education, the participants were subjected to eight hours of self congratulation, interspersed with crude and often bizarre salesmanship. After being requested to consider the Aussat Scenario in respect of the total professional environmental interface; informed of schemes where facsimile machines and personal computers were provided free of charge to learners, and finally shown an international video conference set up at unimaginable expense, Technophobia rapidly set in.

It was aggravated by the fact that none of the technical demonstrations functioned properly, with the teleconference session being a masterpiece of organisational and technological inadequacy. After being told that almost every example given was a small scale trial, it became obvious that this area has more pilots than QANTAS. What a pity we have so few navigators as there seems to be a certain lack of direction.

The newer technologies of communication seem to have had relatively little impact on Distance Education in Australia and the South Pacific for a variety of reasons; technical and ideological.

There is enormous inertia in the educational system, with few incentives to innovate. The academic bureaucracy transforms innovations with ease, often to avoid self transformation. Technology appears threatening, able to record, analyse and disseminate information in a very dangerous manner, so the goal for many is innovation without change; a good thing - but no threat.

This attitude is hardly surprising as education is a labour intensive industry based largely on decentralised decision making. This power structure is threatened by centralised administrative systems and capital intensive operations. Professional autonomy is seen as the first casualty of technological change and is therefore to be avoided. However, this inbuilt resistance to change is not the only reason for inertia. Certain questions remain unanswered: 
- Where in Australia are large scale examples of successful computer assisted learning and computer managed instruction?

- What electronic medium allows cheap, rapid, effective communication with all students?

- How can suitable educational software be developed at a reasonable cost?

- What can be transmitted by satellite to a heterogeneous and scattered student population?

Until satisfactory answers are found, many will believe that the god who jumps from the window of an orbiting garbage can should leave her footprints elsewhere.

Not that technology has been without impact, many institutions have highly effective computerised administrative systems, and technology has helped enormously with typesetting and data recording. Perhaps one of the most instructive examples of high tech is the change over from the Australian Post to Austpac. By using conventional mail the turnaround time for assignments in an institution was 3 months and six days; with Austpac this was reduced to 3 months and six seconds. Unfortunately the time they were left on the marker's desk remains constant. Perhaps the Buddhists were wrong; change not permanence may be an illusion.

\section{References}

New Zealand Official Yearbook (1985).

Ramsay, P. D. K. (1986). The Westland REAP - A Discussion Document. University of Waikato.

Hansen, Jens J. and Beaumont, Allan P. (1986). A Regional Learning Service A West Coast Community College Without Walls. Westland (REAP) Community Education Service.

Dempsey, Bob, (December, 1985). West Coast Continuing Education Survey A preliminary study of provision and needs. Department of Education.

Lange, James C. (May, 1984). Twelve Issues in Australian Tertiary Telecommunications. Unpublished paper for RMIT Conference on satellite communications in Australian tertiary education.

Hansen J. J. and Stimpson D. (April, 1986). Communication Planning and other Issues. DEANZ, the inaugural Distance Education Association of New Zealand Conference - Papers and Proceedings, Westland Community Education Service.

Hansen J. J. (November 1985). Westland REAP and bridging the distance tutor. The Journal of New Zealand Technical Institute Tutors. 
Further details about the subject of this paper can be obtained from the author, Jens J. Hansen, c/ - Westland REAP, PO Box 268, Hokitika, West

Coast, New Zealand. Based on a paper presented at EdTech'86,

International Educational Technology Conference and Exhibition,

University of Western Australia, Perth, 2-5 December 1986.

Please cite as: Hansen, J. J. (1987). Introducing a teleconferencing network to the most remote region of New Zealand: Or forgiveness is easier to achieve than permission. Australian Journal of Educational Technology, 3(2), 151-172. http:/ / www.ascilite.org.au/ajet/ajet3/hansen.html 